Int. J. Electrochem. Sci., 14 (2019) 10983 - 10999

International Journal of

ELECTROCHEMICAL

SCIENCE

WWW.electrochemsci.org

\title{
Electrochemical Investigation of Passive Film Properties on Low Alloy Steel Rebars in Cement Extract and Saturated $\mathrm{Ca}(\mathrm{OH})_{2}$ Solutions
}

\author{
Shimin Li ${ }^{1}$, Wei Liu ${ }^{1, *}$, Yueming Fan ${ }^{1}$, Yutao Wang ${ }^{1}$, Banthukul Wongpat ${ }^{1}$, Baojun Dong ${ }^{1}$, \\ Yonggang Zhao ${ }^{1}$, Zhentao Wang ${ }^{1}$, Yanliang Zhou ${ }^{1}$, Thee Chowwanonthapunya ${ }^{2}$, Xiaogang Li ${ }^{1}$ \\ ${ }^{1}$ Corrosion and Protection Center, Institute for Advanced Materials and Technology, University of \\ Science and Technology Beijing, Beijing 100083, China \\ ${ }^{2}$ Faculty of International Maritime Studies, Kasetsart University, SiRacha 20230, Thailand \\ *E-mail: weiliu@ustb.edu.cn
}

doi: $10.20964 / 2019.12 .75$

Received: 7 May 2019 / Accepted: 16 July 2019 / Published: 29 October 2019

In this paper, the differences in the passivation behaviours of low alloy steel rebars in saturated $\mathrm{Ca}(\mathrm{OH})_{2}$ solution (SC) and cement extract solution (CE) were studied by Mott-Schottky, XPS and cyclic potentiodynamic polarisation (CPP) analyses. The results indicate that the formation rate of a passive film in SC is faster than that in $\mathrm{CE}$ at the initial stage of immersion. With the same passivation time, the passive film that formed in CE has a lower self-corrosive current density, a greater film resistance, a thicker film and better stability than the film formed in SC. The passive films formed in SC and CE have the same composition, and they both exhibit n-type semiconductor characteristics, but the passive films formed in CE have a lower donor carrier concentration and better compactness than those formed in SC. The unpassivated steel has a higher critical $\mathrm{Cl}^{-}$concentration in SC. However, after the steel rebar is passivated for 7 days, the critical $\mathrm{Cl}^{-}$concentration in $\mathrm{CE}$ is higher than that in $\mathrm{SC}$. The critical $\mathrm{Cl}^{-}$ concentration of passivated steel rebars is 4 times higher than that of unpassivated steel rebars, which indicates that passive films can significantly improve the pitting corrosion resistance of steel rebars.

Keywords: Low alloy steel rebars, Mott-Schottky, Cyclic potentiodynamic polarisation, Passive film, Critical $\mathrm{Cl}^{-}$concentration

\section{$\underline{\text { FULL TEXT }}$}

(C) 2019 The Authors. Published by ESG (www.electrochemsci.org). This article is an open access article distributed under the terms and conditions of the Creative Commons Attribution license (http://creativecommons.org/licenses/by/4.0/). 